\title{
Da plasticidade do crime ao acesso à informação em relatos de homicídios: vicissitudes decorrentes de experiências violentas
}

\author{
Alex Medeiros Kornalewskï \\ http://orcid.org/0000-0002-8852-3054 \\ Francisco Ramos de Farias ${ }^{I I}$ \\ http://orcid.org/0000-0002-2966-077X \\ ${ }^{I}$ Universidade Federal do Estado do Rio de Janeiro, RJ, Brasil. \\ Doutor em Memória Social. \\ ${ }^{I I}$ Universidade Federal do Estado do Rio de Janeiro, RJ, Brasil. \\ Doutor em Psicologia.
}

http://dx.doi.org/10.1590/1981-5344/4178

O artigo disserta sobre as múltiplas implicações decorrentes do crime, sua relação com os efeitos traumáticos e suas consequentes rupturas nas cadeias de memórias. A metodologia aplicada é a análise a partir de dois relatos de pessoas distintas que praticaram o ato de homicídio, haja vista a multiplicidade de violências que são narradas, intencionalmente ou não, por estes sujeitos, além das experiências serem representativas do social. As investigações sobre violência estão ligadas a tríade: crime, trauma e informação, sendo estas subramificações empregadas, em certa medida, na tecitura da própria violência. Verifica-se que a construção de protocolos de acesso à informação e análise das restrições informacionais é salutar para a implementação de 
políticas públicas para as pessoas presas ou egressas do sistema prisional.

Palavras-chave: violência. Crime. Memória. Acesso à informação. Narrativa autoral.

\section{From the plasticity of crime to access to information in homicide Narratives: vicissitudes arising from violent experiences}

The article discusses the multiple implications of crime, its relation to the traumatic effects and its consequent ruptures in the chains of memories. The applied methodology is the analysis from two reports of different people who practiced the act of homicide, given the multiplicity of violence that are narrated, intentionally or not, by these subjects, besides the experiences are representative of the social. Investigations into violence are linked to a triad: crime, trauma, and information, and these sub-ramifications are employed to some extent in the fabric of violence itself. It is verified that the construction of protocols of access to information and analysis of the informational restrictions is salutary for the implementation of public policies for the people prisoners or egress of the prison system.

Keywords: violence. Crime. Memory. Access to information. Authorial narrative.

Recebido em 25.10.2019 Aceito em 17.03.2021 


\section{Introdução}

Discorrer sobre a questão do homicídio envolve uma miríade de questionamentos, equívocos, desinformações e problemas inerentes ao campo jurídico, social, psicológico, histórico e demais esferas no qual se escreve sobre um ato de morte provocado pelas mãos humanas ao invés do ceifar realizado constantemente pela natureza. Todavia, três pontos serão analisados no decorrer da presente análise. Primeiro, o fato de que não podemos realizar discussões que desconsiderem a relação de inúmeras esferas do conhecimento no tocante ao homicídio. Segundo compreender que, em maior ou menor grau, o ato citado estabelece pontos de ligação com três células conceituais: crime, trauma e informação. Terceiro, não podemos pressupor, ou perpetuar o revés do equívoco, de que a tríade supracitada remete a aspectos unicamente negativos, haja vista que também podemos discorrer sobre seus respectivos vieses estruturantes. Cabe-nos destrinchar um pouco mais a linha de raciocínio inerente aos três pontos apresentados.

Em linhas gerais, podemos observar inúmeras áreas do conhecimento que abordam o objeto homicídio: psicopatologia forense, direito penal, balística, perícia grafotécnica e um vasto campo de saber que versa sobre a questão da morte provocada por outrem. Contudo, analisar o outro lado do espelho, ou seja, não o viés unicamente da ação, mas a conjuntura que remete ao homicídio, partindo do pressuposto de que há, em sua maioria, um continuum indiviso consciente que envolve o antes, durante e o depois da ação (BERGSON, 2009), demanda uma explicação mais complexa e não meramente didática.

Essa questão torna-se mais clara quando aplicarmos nosso olhar para a divisão didática entre os diversos campos do saber. Em determinados momentos, a ciência busca soluções pelas quais um campo pode prover condições de pensamento, mas não necessariamente uma solução. Nesse momento surge a necessidade de procurarmos respostas em campos que propiciem diálogos e mais ainda, um processo de dialogia, no qual os diversos campos do saber contribuem para a resolução de uma determinada questão, ao mesmo tempo em que adquirem novas ordens construtivas de conhecimento. Em suma, as questões atuais sobre a problemática do homicídio devem ser vistas mais do que pelo viés didático, mas, principalmente, pelo viés da transversalidade, pois as pesquisas sobre o homicídio não podem negligenciar em seus relatos, discursos e documentos técnico-científicos a existência de uma construção de conhecimento transdisciplinar que, para além da urgência na resolução de questões complexas, promove novos "jogos de saber e poder, desestabilizando as regras sobre as quais havia consenso e propondo novos discursos e novas práticas de pesquisa" (GONDAR, 2016, p. 22). 
Outro aspecto pertinente é que não há meios de desvencilharmos, com exceção de um viés didático, da existência do entrelaçamento do homicídio com as esferas do crime, do trauma e da informação. Não apenas no campo científico, porém mais ainda no senso comum, averiguase um equívoco de propor os termos crime e violência como sinonímias. É a partir da ruptura de "mecanismos que tecem a teia dessas relações de convívio - e o rearranjo permanente dos papeis sociais - [que] alimenta situações potenciais de violência" (LESSA, 2004, p. 281). Vale ressaltar que todo crime parte de um processo violento, mas nem toda violência é categorizada como um crime. Muitas ações, falas e gestos podem ser identificadas como violência (ofensas verbais, divergências de tratamento no ambiente de trabalho, casa, escola; sarcasmos, gestos ofensivos com as mãos) e demais exemplos que não constam como crimes na maioria das culturas. Pode-se constatar que um sorriso, um silêncio ou o simples fato de "não fazer nada é a coisa mais violenta que temos a fazer" (ZIZEK, 2014, p. 169).

Em aditamento, a esfera da violência é ampla e contraditória, haja vista que muitos atos tipificados em lei como crimes, podem, em determinadas circunstâncias, ser legitimadas por uma determinada cultura ou constituição. Em exemplo, podemos citar a pena de morte, adotada por países como Estados Unidos, Irã, China, Coréia do Norte; a possibilidade de revogação dos direitos humanos no caso de guerra, tal como consta no artigo 50, inciso XLVII da Constituição da República Federativa do Brasil, em vigor desde 1988; o artigo $55^{\circ}$ e $56^{\circ}$ do Código Penal Militar brasileiro, que prevê a morte por fuzilamento; os ritos culturais de determinados países como a Índia, no qual a mulher, cujo marido morreu, só é vista como um ser de honra se praticar o Sati, prática centenária hindu, em que a mulher, comumente vestida de noiva, comete o suicídio ao se atirar em uma pira funerária; ferimentos, por vezes letais, também eram comuns nos rituais; os sacrifícios de crianças feitas pelas próprias mães em Cusco no período pré-hispânico; o ritual antropofágico que era realizado pelos tupinambá com os presos, em prol do fortalecimento do vencedor ao se apropriar das qualidades do subjugado (BAYARD, 1996; LESSA, 2004).

A própria esfera da violência perpassa uma transversalidade de campos do saber, para além dos distintos, mas não divergentes, grupos teóricos, dentre os quais cabe citar: primeiro, a violência investigada pelo viés tecnicista em prol do entendimento das realidades sociais; segundo, o viés que analisa a essência da violência como algo que resulta dos efeitos sociais provocadas pela industrialização e urbanização; terceiro, no qual a violência é entendida por intermédio de estratégias de sobrevivência do corpo social sobrepujado pelos aspectos inerentes ao capitalismo; quarto, discorre sobre a violência como uma dimensão que prove o aumento da 
criminalidade por conta da ausência das assistências estatais previstas em lei em prol do emprego de seu poder repressivo utilizando-se da máquina jurídica e policial (MINAYO; SOUZA, 1998). Todavia, entende-se que as investigações sobre a problemática do crime, está atrelada as conceituações da violência, trauma e informação, haja vista que são fatores que se entrelaçam no decorrer das experiências registradas na vida das pessoas presas.

Quanto a relação entre a violência e o trauma é mister o desenvolvimento de dois apontamentos. Primeiro, deve-se discorrer sobre os efeitos traumáticos oriundos da condição social do sujeito ou ocorridos após o ato de homicídio; segundo, investigar o dúplice viés positivo e negativo do trauma, haja vista que o mesmo pode ser o eixo que afeta o sujeito, ao mesmo tempo em que possibilita caminhos para promover o equilíbrio (ASSMANN, 2011). Não é raro vermos não apenas nas narrativas das pessoas presas, mas também em entrevistas e informações concedidas em diversas mídias ou tipologias documentais nos quais o sujeito demonstra os impactos sofridos em períodos distintos, cujo problema perdura por meses, anos, décadas ou mesmo além de uma determinada geração, enquanto também podemos verificar as inúmeras possibilidades de equilíbrio, elaboração, superação e criação por parte das pessoas, de forma a surtir um efeito positivo para si ou mesmo para outrem.

Quanto a questão da informação e da violência, temos uma relação fragilizada no campo da literatura científica, pois além das poucas fontes, os pequenos casos de promoção adequada da informação sobre a violência, por exemplo, as pesquisas e comissões desenvolvidas para investigar os atos produzidos no período da ditadura, investigações de excessos promovidos por policiais e demais relações Estado x sociedade, temos uma grande quantidade de problemas no que diz respeito a própria promoção da informação, ou seja, o acesso à informação é uma questão negligenciada, ainda mais quando pensamos em fontes construídas a partir das falas de pessoas presas. Contudo, Têm-se uma miríade de mídias que disseminam informação estereotipada, equivocada ou parcial quanto aos crimes serem praticados apenas por determinadas categorias, ao mesmo tempo em que ressalta o direito de defesa, segurança e demais preceitos legais aos ditos "cidadãos de bem", evocando uma moldura binária entre "bandido" $x$ "pessoas de bem", como se a problemática dos conflitos com a lei não fossem praticados por outras camadas existentes no corpo social (ROLIM, 2018).

Destarte, é crível afirmar que a questão da informação se relaciona com a violência, a priori, quando perscrutamos suas dificuldades, ou seja, quando analisamos que há duas dimensões contrárias a lógica do acesso à informação: de um lado, temos as restrições formais, operadas muitas 
das vezes pelo viés jurídico, institucional, que ao mesmo tempo pode se mostrar necessária, mas também inviabilizar pesquisas, revisão e elaboração de políticas públicas nos campos da saúde, assistência social, educação e afins; de outro lado, temos as restrições informais em que um simples "não" proferido por um agente público de segurança - sem necessariamente utilizar-se do amparo legal - pode anular avanços em pesquisas, ignorar 0 acesso das pessoas presas a determinadas informações, inadequação do espaço físico em que os documentos são armazenados e demais fatores pelas quais o mesmo poderia ter acesso com base na Lei de Execução Penal (LEP) e afins (PEREZ; MENEZES, 2007).

Diante do exposto, o presente trabalho toma como análise o estudo de caso de duas pessoas presas, cujas narrativas constam no dossiê finalizado pelo pesquisador Francisco Ramos de Farias construído a partir do projeto de pesquisa intitulado $O$ ato criminoso como modalidade de gozo: subjetividade perversa e ato perverso, financiado pelo Conselho Nacional de Desenvolvimento Científico e Tecnológico (CNPq). Alguns pontos devem ser explicados quanto a escolha do presente dossiê e escolha das narrativas. Primeiro é a questão da situação, tendo em vista que o projeto foi finalizado entre os anos de 1995 e 1999, o que contribui na celeridade do processo de pesquisa, pois o dossiê apresenta as narrativas de 56 presos que praticaram crimes diversos, sendo que em sua maioria há o registro de homicídio já transcritos para o desenvolvimento de futuras pesquisas dentre os quais o presente artigo também se enquadra. Segundo, não houve necessidade de registrar o dossiê no comitê de ética, tendo em vista que o projeto já foi finalizado; pelo fato de que as pessoas presas não serão identificadas no artigo além do fato de que o arquivo consultado se encontra registrado pelo pesquisador na seção de direitos autorais da Fundação Biblioteca Nacional, sob o número: 757.783, livro: 1.469, folha: 274. Terceiro, o dossiê apresenta anuência do próprio autor para ser consultado e utilizado na presente pesquisa, respeitando os direitos morais e patrimoniais, além de estabelecer a citação e indicação de origem da obra, tal como preza o art. $46^{\circ}$, inciso III da Lei que versa sobre os direitos autorais (BRASIL, 1998).

Quanto a metodologia, priorizamos as narrativas de duas pessoas presas para elaborar o estudo de caso pois essa ferramenta corrobora com o uso de histórias de vida desde os estágios preliminares da pesquisa até o uso desses relatos como corpus teórico, no âmbito da pesquisa social (GOODE; HATT, 1975). A metodologia em questão não determina o quantitativo de pessoas e narrativas necessários para o estudo, mas viabiliza o uso de dados inerentes a uma pessoa, família, instituição. Além disso, nos permite averiguar os fenômenos humanos como parte da realidade social, dito de outra forma, "o ser humano se distingue não só 
por agir, mas também por pensar sobre o que faz e por interpretar suas ações dentro e a partir da realidade vivida e compartilhada por seus semelhantes" (MINAYO, 2016, p. 20).

\section{Violência e crime}

A primeira dimensão que se entrelaça com os pressupostos conceituais da violência, e muita das vezes em situação de sinonímia, é a noção de crime. O crime como uma propedêutica e, por conseguinte, como um campo científico iniciou-se no século XIX, atrelado a investigação dos feitos do criminoso e não do crime propriamente dito, haja vista que as premissas que respaldavam o respectivo campo parisiense de estudos advinham da chamada antropologia criminal, cuja ênfase era o comportamento humano (ROBERT, 2011). Em aditamento, a noção de crime e da pessoa criminosa também se atrela ao conjunto de questões de intervenção médico-sanitária, tais como: "civilização dos costumes, [...] organização familiar e na prevenção de comportamentos desviantes ou transgressores" (MITJAVILA; MATHES, 2016, p. 848). Em essência, priorizava-se investigações que apresentassem respostas para o porque do sujeito cometer determinadas ações, a corroborar com a entrada desses sujeitos no critério de seres que não se enquadram em suas respectivas sociedades, de forma que os estudos sobre a criminalidade se direcionam para duas linhas: a primeira, pressupõe a investigação das motivações individuais; a segunda, questiona quanto aos "processos que levariam as pessoas a se tornarem criminosas" (CERQUEIRA; LOBÃO, 2004, p. 3).

Todavia, apesar das diversas teorias inerentes ao campo da criminologia, dentre as quais podemos citar o modelo ecológico, cuja sistemática emprega um "modelo integrado para explicar a violência, cujo enfoque se dá nos vários níveis estrutural, institucional, interpessoal e individual (CERQUEIRA; LOBÃO, 2004, p. 24), ainda assim, emprega-se em demasia a lógica da correção punitiva, sendo esta imposta por meio da disciplina, desde a cultura da soberania, no qual o sujeito era punido com múltiplas e complexas torturas até a morte, ambos os casos expostos em lugares públicos para prover o ensinamento, ou política do medo, a partir da comunicação do soberano para com os seus séquitos, avisandoos de que a imagem da tortura ou da morte em questão é para que outros não repitam o crime em questão (FOUCAULT, 2011). Todavia a lógica de enquadrar o sujeito que desvirtua pela lógica do crime segue desde a cultura da soberania, passando pela cultura disciplinar, e ou atualmente pela cultura do controle, no qual as possibilidades criminais se aperfeiçoam conforme as singularidades mostram-se anômalas a determinados segmentos sociais. Em suma, têm-se um mecanismo penal, reforçado pelo saber jurídico e médico e seus instrumentos de detecção e 
administração (MITJAVILA; MATHES, 2016), em consonância com o discurso legitimado em sociedade do conceito de justiça, aplicando leis próprias em delitos específicos, sob "formas particulares de sanção, suas instâncias de julgamento" (FOUCAULT, 2011, p. 171).

Apesar da constante atualização do conceito de crime, e suas respectivas tipificações descritas no Código Penal, é comum a ebulição de críticas quanto a subjetividade e ausência de transparência quanto aos critérios utilizados para elencar e definir as categorizações de crime e como aplicá-las nos respectivos casos, haja vista que todo crime apresenta a categoria de violência, mas a noção de violência é ampla e muita das vezes apresenta segmentos que não são dispostos na letra da lei ou sofrem interpretações diversas. Em exemplo, podemos refletir sobre o fato de o homicídio ser tipificado como crime, mas não ser enquadrado dessa forma quando falamos dos casos de guerra, previsto no artigo 50, inciso XLVII da Constituição da República Federativa do Brasil, em vigor desde 1988. Para além da subjetividade quanto a tipificação de assassinato ser enquadrado como crime de homicídio ou não, cabe discorrermos sobre as divergências de tratamento penal aplicado nos sujeitos que se encontram sob tutela do Estado nas unidades prisionais. Para fins de segurança iremos chamar o interno de F. O mesmo é natural de Petrópolis, Rio de Janeiro, estado civil solteiro e era funcionário de hospital antes de sua entrada na prisão. Perguntado sobre o motivo que o levou a ser preso, ele expõe a seguinte narrativa:

157 parágrafo terceiro - assalto à mão armada seguido de homicídio. Fui preso um ano depois do crime, não tinha prova, não tinha nada. O advogado disse pra eu confessar que ele ia aliviar. Mas aí eu fui condenado. Ele queria era um condenado e não um réu. Foi aí que me deram 23 anos de cadeia e fugi da 105 DP em Petrópolis. Acabei sendo recapturado em Búzios. Em Búzios tem muita mineirada ${ }^{1}$. Os policiais pegam e você paga e não é trazido preso. Houve uma vez que os policiais não levaram o dinheiro. Deixaram com o advogado, mas o advogado não fez o acerto porque os policiais não aceitaram que ele fosse o intermediário ( $F$., 1996, p. 30).

$O$ interno $F$. inicia sua narrativa apresentando uma categoria que passa a ser sua marca dentro da unidade prisional, e provavelmente a marca que o seguirá como um estigma dentro do âmbito social: 157. Para além do número de registro de entrada das pessoas presas, é natural os mesmos também serem lembrados pelos números representativos de seus crimes, tal como descrito no Código Penal. Robert (2011, p. 7) afirma o seguinte: "o crime traz à lembrança o ápice da ordem social, mas, por outro, seus precipícios". Pode-se dizer que de fato, pela ótica 
dos códigos jurídicos, a tipificação do crime é um meio de evocar os inúmeros pontos vistos como perturbador, violento e passível de punição por determinado segmento social. Vale ressaltar que há variações quanto ao método, tempo ou mesmo ausência de punição de acordo com determinadas esferas sociais, por exemplo, nem todo país adota, de forma convencional, a punição com morte, tempo de privação de liberdade (ex. casos de homicídio) ou mesmo punição (morte ocasionada por legítima defesa, país em situação de guerra etc.). Podemos verificar que essa "ordem social" é plástica, haja vista que determinadas questões são resolvidas por método, tempo e justificativa diferenciada, além das punições informais que são empregadas fora da sistemática prevista em lei, tal como é o caso do encarceramento em massa, superlotação e o descumprimento da LEP quanto a separação dos internos, que deveria considerar a tipificação criminal das pessoas, ao invés de aloca-los mediante seu pertencimento, intencional ou não intencional, a facções criminais (ROLIM, 2018). Além disso, impera uma prática de negligência quanto as obrigações legais do Estado de prover resoluções no campo econômico e social em prol de uma luta contra a criminalidade que pune uns enquanto silencia, omite ou esconde outras problemáticas também tipificadas criminalmente, em um "permanente espetáculo moral" que permite aos dirigentes de Estado a endossar simbolicamente a sua autoridade (WACQUANT, 2004, p. 3).

Além da "ordem social" também há os precipícios, o que nos faz pensar sobre o trecho em que $F$. apresenta vários pontos que permitem múltiplas perspectivas: tempo de pena (23 anos), apelo para prover outra versão para o crime por parte do advogado, fuga da DP, "mineirada" e advogado intermediador de pagamento de soltura da pessoa. Esses pontos são passíveis de enquadramento criminal e perpassam a narrativa do próprio interno, apesar de serem fatores não correspondentes ao crime pelo qual o mesmo cumpre na prisão. Todavia, é comum vermos uma aplicação reducionista das tipificações criminais nas diversas mídias, que potencializam o ato pelo qual a pessoa presa é registrada ao adentar nos tramites jurídicos e, por conseguinte, exercer o cumprimento de pena nas unidades prisionais, mas de sobremaneira não chegam a sociedade, por meio dos suportes comunicacionais, a conjuntura do crime em si, a narrativa profunda que envolve o antes, durante e os efeitos possíveis depois do crime, além das circunstâncias pelas quais o mesmo irá responder não apenas até o chamado trânsito em julgado, mas também durante sua estadia na prisão e seu percurso de vida ao tornar-se uma pessoa egressa do sistema prisional. Em síntese, não há transparência, porém há superficialidade, não há informação, nem mesmo um processo salutar de comunicação, mas sim uma banalização da interface 
comunicacional que "leva a forma social à indiferença" (BAUDRILLARD, 1992, p. 18).

Outrossim, a subjetividade jurídica que mantém padrões de temporalidade distintos na prisão de determinadas categorias em prol de outros que são punidos pelo mesmo crime, mas com um cumprimento de pena menor, regimes diferenciados e até mesmo respondendo em liberdade com a possível consequência de arquivamento do processo, são questões que se apresentam apenas sob a premissa banal de diferenciação das categorias de pessoas mediante condição financeira, grau de instrução e diferenciação de amparo estatal o que fere, ou pelo menos demonstra por em xeque, o disposto no art. 5 da Constituição da República Federativa do Brasil, que afirma: "todos são iguais perante a lei, sem distinção de qualquer natureza, garantindo-se aos brasileiros e aos estrangeiros residentes no País a inviolabilidade do direito à vida, à liberdade, à igualdade, à segurança e à propriedade, nos termos seguintes" (BRASIL, 1988, p. 2). Em aditamento, cabe-nos refletir sobre a afirmação de Grosser (1989, p. 17-17, tradução nossa): "Um crime é o equivalente a outro crime da mesma natureza e do mesmo tamanho quando os seres humanos foram vítimas. Todo homem vale todo homem, então qualquer ataque à sua integridade é criminoso". Logo, tanto a premissa citada quanto o disposto na lei advogam em favor da igualdade e dos pressupostos criminais aplicáveis de forma isonômica, porém as divergências entre o tratamento penal aplicado ao mesmo crime, muitas das vezes nas mesmas condições de prática do ato, mas com diferenciações nas categorias sociais ao qual o sujeito pertence, ainda se mostra como uma trilha muito inóspita a ser desbravada e revisada por meio de uma transparência necessária desde o processo de julgamento até a finalização dos respectivos recursos, com o intuito de dirimir a distância entre determinadas categorias provocadas por esta tipologia de violência social (MINAYO; SOUZA, 1998).

Dando continuidade, o interno $F$. narra outras duas questões: a "mineirada" e a função de intermediador feita pelo advogado para proceder com a soltura, ou não, da pessoa presa. Verifica-se duas questões que também perpassam por uma comunicação informal, velada e de difícil elucidação por parte dos atores envolvidos, haja vista que o processo envolve apenas os atores que exercem a prática criminosa. Verifica-se uma violência no ato de atribuir a decisão de liberdade a pessoas que nem seguem os ritos aplicáveis a função de juiz, tendo em vista que tanto o policial quanto o advogado, dotados de intencionalidade financeira ilícita, podem proporcionar um afrouxamento das leis em prol da desobediência do próprio Código Penal.

Eis que a balança da justiça pesa somente para aqueles que não compactuam com os padrões definidos por essa comunicação informal e, 
principalmente, para aqueles que - independente do interesse na ilicitude - não possuem condições financeiras de pagar por sua liberdade, sendo este procedimento um simples meio de prover julgamentos do outro por meio de suas contradições do ontem, ao mesmo tempo em que se aplica os mesmos critérios contraditórios no hoje, ou seja, a possiblidade de anular um crime, em prol de outro (GROSSER, 1989).

Portanto, quando $F$. evoca uma narrativa que apresenta inúmeras tipificações criminais, também é possível ver atos violentos que são praticados por outros agentes, que não o ator primeiro do crime, mas que, em sua maioria, não são registrados dentro do âmbito de julgamento penal. Tal como descrito no Decreto-lei N. 2.848, de 7 de dezembro de 1940, a possibilidade de trocar o crime disposto no art. 157 - parágrafo terceiro (assalto à mão armada seguido de homicídio) cometido por F. pelos crimes descritos no art. 317 - parágrafo segundo (corrupção passiva seguida de infração de dever funcional) praticada pelo policial, somado ao art. 333 (corrupção ativa) realizada na tentativa de intermediação na soltura ilícita do sujeito sugerida pelo advogado (BRASIL, 1940), reforçam o quão possível é exercer o enquadramento de uma ação, haja vista que enquadrar é estabelecer rupturas com o contexto, na tentativa benéfica ou maléfica, lícita ou ilícita, de prover novos contextos, novos arranjos, sempre dependente dos atores envolvidos, sem, contudo, prover necessariamente um efeito consensual (BUTLER, 2015).

$O$ pequeno trecho narrado pelo interno $F$. nos evoca uma problematização que atravessa o conceito de crime em todas as direções, pois dizer que o crime é o que foi tipificado pelas leis descritas no Código Penal, sendo este construído e revisado de acordo com as urgências oriundas das convenções sociais, se não é reduzir ao menos enclausura os múltiplos olhares necessários para se aplicar ao conceito de crime e os percalços que envolvem o crime mor, ou seja, o crime pelo qual um determinado sujeito é julgado, enquanto diversas outras perspectivas de crime mantém-se no processo de ocultamento social, no qual sujeitos, grupos e instituições estatais ou sociais expressam inoperância, e inobservância, para o contexto criminal, aplicando seu olhar unicamente no tocante penal a um determinado segmento da sociedade. Esse efeito se fundamenta por intermédio de uma política de penalização da miséria, ou criminalização da pobreza, no qual julga-se apenas o crime praticado pelo sujeito, em detrimento de toda uma rede que o circunda, de forma a ignorar diversas tipificações criminais e atores, muita das vezes envolvidas, de forma direta ou indireta, na comunicação de um determinado crime que esteja em evidência. Em contrapartida, pode-se verificar um "enfraquecimento da capacidade de intervenção social do Estado e do abandono de suas prerrogativas diante da figura 
supostamente onipotente do 'mercado', isto é, a extensão da lei econômica do mais forte" (WACQUANT, 2011, p. 149).

É mister ressaltar que nem todos os casos de homicídio e demais tipificações criminais podem ser categorizadas dentro de um contexto de ausência do Estado social em prol de um exercício do Estado penal, pois essa premissa é facilmente refutada quando evocamos três princípios: primeiro, a singularidade inerente a cada sujeito, apto para escolher as vias ao qual irá seguir no decorrer de sua vida; segundo, o fato de que muitos sujeitos que se encontram nas mesmas condições de ausência de amparo social, não necessariamente seguem pelo caminho do crime (MINAYO, 2015); terceiro, tal como vimos na narrativa de F. muitos desses atores que fazem parte da conjuntura criminal são juízes, policias, advogados, pessoas que, em sua maioria, tiveram acesso a estrutura social e financeira nunca existente a determinadas categorias mais pobres e sem amparo educacional, por exemplo, contudo, mostram-se como sujeitos passíveis ao exercício do crime tal qual aos que são julgados. Verifica-se que é crucial o estabelecimento do exercício de uma visão de contexto, de ampliação do olhar, e não apenas do emprego da punição seletiva, aliado a estruturação do Estado social, para que tenhamos uma diminuição de violências veladas e, por conseguinte, não tipificadas como crime, ao invés de uma escolha dos crimes que devem ser julgados, ou seja, aplicar um esforço institucional e social para diminuir os incontáveis equívocos realizados tais como se todos os homens fossem autorizados a julgar leviana e imprudente tal qual Minos, cujas ilicitudes "mede junto à entrada [...] e ele, que entende de pecado, a cada uma no inferno seu lugar mostrava" (ALIGHIERI, 1984, p. 138).

\section{Violência e trauma}

Discorrer sobre a relação entre crime e violência nos leva a não negligenciar as intempéries provocadas por uma problemática recorrente nas pessoas envolvidas nos acontecimentos, dentre os quais também se inclui os encadeamentos provocados pelo trauma. À vista disso, é mister estabelecer uma breve explanação sobre o conceito de trauma, antes de embrenharmos nas nuances conflituosas do trauma e da violência inerente não apenas a narrativa do crime, mas sim, em uma conjuntura maior, que pode aplicar-se aos atores, sem distinção de quem e dentro de uma temporalidade que se apresenta não apenas durante o ato ilícito, mas antes ou mesmo depois do acontecido tipificado nos termos da lei. Em termos históricos, especificamente na área da história das ciências, constata-se que o uso do termo trauma, deriva de um acontecimento, uma violência física, "definido pela invasão e golpeamento de um agente externo sobre o corpo físico, que por efeito desse mesmo golpe é lesionado, ferido ou machucado" (ENDO, 2013, p. 43). 
O termo trauma permite uma dissecação quando analisamos sua definição elementar, pois vários aspectos são traçados na sua conjuntura. Primeiro, invasão, golpe, ou seja, um acontecimento que afeta de uma determinada forma um corpo, que abala, causa transtornos (ASSMANN, 2011). Em segundo lugar, a origem desse acontecimento envolve a noção de temporalidade, por exemplo, um acidente de bicicleta, uma briga, uma queda ou qualquer outro acontecimento motivador pode atuar como causa precipitadora, estabelecendo um elo a partir de uma disfunção mínima a ponto de ocasionar transtornos qualificados como trauma (FREUD, 2016). Terceiro, é a não obrigatoriedade do processo de ab-reação da causa precipitadora, pois a lembrança da causa, "mesmo quando não foi abreagida, entra no grande complexo de associação, ocupa um lugar de outras vivências que talvez contradigam, sofre uma correção por outras ideias" (FREUD, 2016, p. 22-23).

A partir dessas premissas, consolidou-se o conceito de trauma psicológico, constata-se que uma experiência vivida pelo sujeito pode gerar no "a posteriori" rupturas no psiquismo, ocasionando um excesso de difícil simbolização e, por conseguinte, prover inúmeras lacunas mnésicas (FARIAS, 2011; BOHLEBER, 2007; ASSMANN, 2011). Eis que novos aspectos surgem quando pensamos o conceito de trauma em uma perspectiva psicológica: primeiro, o ato, a violência transforma-se em algo que afeta o corpo em linhas não físicas, porém mentais, abala o emocional, propicia efeitos psicossomáticos, ou seja, problemas físicos que se iniciam por intermédio das afecções psíquicas; segundo, o fator do excesso como algo que torna-se insuportável, transborda, a ponto de causar danos, o que nos faz pensar nesta tipologia de trauma como algo que possui uma escala, uma espécie de medição, distinta de acordo com a singularidade e iminência dos efeitos no respectivo corpo; terceiro, o fato de que essa tipologia de trauma provoca rupturas na memória, lacunas, incitando ao sujeito a incapacidade primeira de narrar o que lhe afetou, colocando-o em um estado de repetição constante, haja vista que o abalo bloqueia a capacidade do corpo de seguir em frente, comunicar a experiência e seguir com sua rotina de vida em toda sua plenitude. Para tornar mais claro, e seguirmos com as nuances que entrelaçam a categoria de trauma e de violência, é convidativo seguirmos com mais um trecho do interno $\mathrm{F}$. Ao ser interrogado sobre o que ele pensa sobre o crime e, em seguida, sobre se o mesmo experimentou alguma tipologia de droga ilícita, o mesmo narra o seguinte:

Aos 11 anos comecei com maconha. Aos 13 anos comecei com cocaína. Aí meus pais descobriram. Tiraram o dinheiro, começaram a me vigiar. Aí comecei a tirar alguma coisa de casa. Aí saí de casa e fui morar com uns amigos. Continuava a roubar. Depois quebrava a cara e voltava pra casa, buscando a proteção dos pais. Até hoje 
continuo usando numa escala bem menor porque aqui tem menos e é mais cara. Eu não sei te explicar, mas é uma maneira de fugir da depressão. Até pra suportar isso aqui é preciso encontrar uma saída. Antes eu já tinha depressão por problema familiar, por problema de droga. Tive muitos problemas com meus pais. Minha mãe bebia muito. Era alcoólatra. Meu pai viajava muito. Ela acabava com o bar dentro de casa. Eu era menor, ficava vendo aquilo tudo e ficava cheio de problemas. Isso me influenciou muito ( $F ., 1996, p$. 32).

Da mesma forma como a relação entre o crime e a violência - no qual todo crime advém de um acontecimento violento, mas não necessariamente toda violência é tipificada como um crime, também podemos aplicar a premissa de que todo trauma decorre de um ato violento, contudo, nem toda violência torna-se necessariamente um trauma. Para complementar, é crível afirmar que o trauma não se aplica apenas ao agente passivo no momento do acontecimento, mas também pode ser aplicado ao agente ativo, em outras palavras, um ato violento pode gerar rupturas e, por conseguinte, implicações traumáticas tanto na vítima quanto no algoz. A subjetividade de cada pessoa pode escrever caminhos e, por conseguinte, afecções de ordem traumática diferentes a partir de um mesmo acontecimento motivador. A ausência de estrutura financeira, amparo familiar e a insuficiência quanto a construção de subsídios para trilhar a própria vida são alguns pontos que podem ser observados como efeitos da ordem de castração, ou seja, quando a questão da falta, por si só, "ao ser captada, é alçada a condição de um acontecimento traumatizante" (FARIAS, 2011: 17). Em aditamento, a própria vitima de um acontecimento precipitador, portanto violento, também pode apresentar um quadro de trauma por conta do processo de recalque, ou seja, velamento de uma lembrança de algo que Ihe causa efeitos danosos no psiquismo; a ocorrência do desmentido, ou a negação, não aceitação, de que um acontecimento violento de fato ocorreu com aquela pessoa entre outras conjunturas possíveis a partir do "a posteriori" (FARIAS, 2011). Têm-se uma miríade de inscrições, que se desenvolvem a partir de um ato violento, que podem acarretar em uma desarmonia e se consolidar, por meio da lembrança, na condição de "um corpo estranho que ainda muito tempo depois de sua penetração deve ser considerado um agente atuante no presente" (FREUD, 2016, p. 21).

Sabe-se que muitos dos efeitos violentos ocasionados à vitima são, de fato, desencadeadores de traumas, porém a literatura é parca quando se pretende discorrer sobre o trauma na concepção do algoz, muito pelo fato do senso comum não atribuir a ordem do trauma aquele que produz o efeito violento e passível de ser traumático, como se o trauma fosse atrelado somente ao sujeito categorizado como agente passivo de um 
determinado acontecimento. Contudo, evocar, por exemplo, a culpa, a vergonha, a raiva e demais métodos de fuga - de viés psicológico ou físico - são prenúncios de que o corpo está ali e sente por um acontecimento. 0 interno F. alega que apresenta o quadro de depressão que perpassa dois momentos de sua vida: o antes e o momento atual no qual se encontra na prisão. Todavia, o mesmo utiliza de uma mesma válvula de escape: as drogas. Claro que não se pode fazer uma análise reducionista das ações que desencadearam o quadro citado e os motivos que o levaram a escolher o uso de maconha e cocaína para fugir da realidade que o abala, mas também não se pode negar a existência de fatores que o afetam: problemas familiares (pai ausente, mãe alcóolica), dificuldades no convívio e escolhas de amigos, problemas no próprio ambiente prisional, ou seja, o interno apresenta um quadro precoce e pernicioso em sua vida, cujas opções, a priori, satisfatórias, porém não resolutivas, se apresentam como satisfatórias na sua vida. Tal como escolhas mefistotélicas, a trazer um caminho fácil para suportar e nos permitir o ato de "livrar-se" dos problemas, mas que, em pouco tempo, o pagamento para essas "resoluções" são cobradas e com altas taxas.

Os trechos narrados pelo interno $F$. demonstram que há uma miríades de violências existentes além das registradas nas fichas criminais, pois em um pequeno trecho pode-se verificar a existência de violência interpessoal (ausência, agressões verbais, visuais), violência cultural (lugar e condição de moradia, discriminações), violência intrafamiliar (realizar ou observar distintas agressões entre parentes) e demais tipologias de violências que demonstram um campo árduo e grande de violências que versam pontos que estão além do simples viés reducionista da agressão física (TOLEDO; SABROZA, 2013). Entretanto, de todas as violências narradas, eis que a violência ocasionada pelas drogas levou o sujeito a responder criminalmente. Cabe questionar: qual o critério que permite judicializar e criminalizar uma droga enquanto outras proliferam na legitimidade, ou mesmo na ilicitude, vendidas em larga escala e não são passíveis de criminalização tanto pelo objeto quanto pelo sujeito que as consome? E antes da judicialização e criminalização, não seria pertinente olharmos para as variantes da violência que perseguem o sujeito muito antes de sua própria existência, por meio de indícios e práticas que acompanham as gerações anteriores e a ineficácia do Estado em prover o amparo social previsto na Constituição?

Sem embargo, discorrer sobre a relação da violência e do trauma não pressupõe uma discussão de âmbito estritamente negativista, pois há de se evocar o lado da criação, da elaboração, necessária para o encaminhamento da vida frente aos abalos psíquicos ocasionados por determinadas violências. Dentre as inúmeras narrativas que demonstram a importância de saber lidar com a violência, impedindo-a de tornar-se um 
trauma, ou elaborando-a em casos de traumas já consolidados no psiquismo do sujeito, trazemos mais um trecho, dessa vez do interno $A$. $O$ mesmo também responde pelo artigo 157, parágrafo terceiro, sendo que consta dois homicídios nesse registro, ao qual o interno alega não ter participado, mas sim do roubo, um ano antes. A questão da ausência de estudo, trabalho (o sujeito foi demitido de dois empregos por conta do processo), desamparo familiar e estatal são questões que o perseguem constantemente proferidas em suas narrativas. Contudo, o interno A. informa que se tornou artesão dentro da prisão:

Eu trabalho aqui dentro. Eu sou artesão, faço nome de pessoas na madeira, faço a escrava Anastácia, faço jarro de madeira. Eu faço mais pra encomenda. No meu cubículo tem, mas é meu, pra mudar mais um pouquinho. Aprendi a fazer isso tudo aqui (A., 1996, $p$. 36).

Cabe-nos pensar que o trauma é possível de ser elaborado, ou seja, é possível anular a essência violenta do trauma, por intermédio da criação, de uma transferência de energia ou por uma identificação. 0 interno A. demonstra essa nova aplicação de energia, por exemplo, ao narrar sua habilidade desenvolvida na prisão, sua nova competência de artesão, constatada por meio das esculturas em madeira e até mesmo serviços em madeira que lhe são encomendados. O trauma que surge por meio das inúmeras ausências, e por que não pensar nelas como violências, atrelado ao próprio ato violento, tipificado como crime de roubo e de homicídio, somam-se no psiquismo transbordando-o e construindo uma barreira que impede o sujeito de narrar as violências com detalhes, sendo algo sempre na condição de latente ou nas palavras de Assmann (2011, p. 279): "um corpo estranho que estoura as categorias da lógica tradicional: ao mesmo tempo interna e externamente, presente e ausente".

Todavia a questão do crime de homicídio é defendida como algo não praticado por $\mathrm{A}$ nos seus inúmeros relatos no presente dossiê, ao mesmo tempo em que evoca sua nova competência, de artesão, e o quanto o mesmo se sente realizado ao confeccionar suas diversas obras. A ausência de amparo institucional - leia-se Estado, família entre outros -, levaria, segundo Kehl (2011, p. 51), a identificar-se "com seu ato e repeti-lo. É aí que ele passa do enunciado 'matei alguém' para 'sou um assassino". Wacquant (2004, p. 6) endossa ao afirmar que o ambiente prisional implica em um vasto campo de violências que exerce constantemente os vetores de humilhações, "desagregação familiar, de desconfiança cívica e de alienação individual". Porém constata-se uma contradição nessa premissa elementar pois o mesmo não se identifica, seja por meio da ação 
ao qual respondeu, e paga criminalmente ficando em situação de privação de liberdade, mas também não se circunscreve no circuito da repetição, pois mesmo que o fato do homicídio seja verídico em sua história de vida, têm-se um apoio não apenas pela confecção de obras de arte, mas também por meio do processo de identificação, tal como podemos verificar a seguir:

Eu sou devoto da escrava Anastácia [...]. Os trabalhos da escreva Anastácia eu não vendo. Tem muitos trabalhos dela lá em casa. Eu sempre faço a escrava Anastácia, mas não pra vender. [...] $A$ história dela me interessou porque ela era escrava e eu também to me julgando um escravo da justiça (A., 1996: 37).

Para além do aspecto da arte como um meio de subverter a trilha da repetição para adentrar na trilha da criação, outra energia que o interno $A$ nos evidencia é sua identificação pela Escrava Anastácia. Esse processo de identificação "é conhecida pela psicanálise como a manifestação mais precoce de uma ligação emocional com outra pessoa" (FREUD, 2013, p. 98). O interessante é que o mesmo apresenta ao longo de sua narrativa trechos em que demonstra não conhecer, de fato, a história completa da escrava Anastácia, mas ressalta que a sua condição de escrava é similar a sua condição, pois o mesmo entende-se como um sujeito impedido de seguir com sua vida por conta da própria justiça.

Ademais, sua condição limitante apresenta uma barreira cujo trauma, oriundo dos crimes e violências sofridas e práticas em sua vida, não se mostram cruciais para definir o seguimento de um caminho que, em tese, permite somente a repetição. O viés do crime "parte do projeto ilusório de busca de satisfação e constitui um esforço torpe e rude do qual o homem se vale para dar cabo do excesso traumático" (FARIAS, 2010, p. 108). Contudo, o viés da criação permite a externalização daquilo que Ihe é latente, permite um estado de profilaxia psíquica, no qual o excesso, outrora em transbordamento, seja canalizado em realizações emocionais, profissionais, artísticas, permite um meio de comunicação no qual cria-se símbolos a partir do que inviabiliza a simbolização, ou seja, as implicações de ordem traumática, aplicando a arte mais do que "uma função comunicante, mas também, com toda probabilidade, uma função simbólica" (BENJAMIN, 2013, p. 72).

Podemos sintetizar o fato de que a plasticidade é um termo atrelado ao conceito de crime e de trauma, pois em ambos os casos a lógica da violência mostra-se como um vetor elementar, ao mesmo tempo em que não necessariamente deve-se incorrer no equívoco de que o resultado da violência, seja qualquer tipificação criminal e ou fatores de ordem 
traumática, podem ser vistos apenas por um único viés reducionista no qual ambos são meramente objetivos e destrutivos. O crime mostra-se por meio de um relativismo que se transmuta não apenas no território nacional, mas principalmente em níveis internacionais, adquirindo perspectivas diferentes ou mesmo não sendo caracterizado como crime em várias circunstâncias; da mesma forma que o trauma não necessariamente é algo somente danoso a trilhar o sujeito para o caminho da repetição ad aeternum, pois é a partir do insignificável que o sujeito pode criar novos caminhos, novos meios para seguir. É mister seguir os passos para a última relação.

\section{Violência e acesso à informação}

Pensar sobre a relação violência e crime, violência e trauma sem entrar na investigação do acesso à informação e seus percalços, é considerar as discussões anteriores como mudas, ou seja, refletir sobre algo que continuará a ficar velado, dito de outra forma, não se aprofundar no problema, a ponto de impedir a visibilidade adequada a presente discussão.

A priori, o conceito de acesso caracteriza-se por algo disponibilizado "em tempo útil, é relevante, tem um preço acessível, é facilmente assimilável, em um idioma, e um contexto que os usuários podem entender e compreender" (GUIMARÃES; SILVA; NORONHA, 2011, p. 15). De antemão, podemos apreender os seguintes pontos para validar 0 status de acesso à informação de uma determinada tipologia documental: imediatismo da informação (disponível quanto o usuário ou tomador de decisão precisa e não quando Ihe é permitido, se assim o for); relevância (o que nos faz pensar nos critérios de relevância de determinada informação não ser definidos apenas pela instituição que detém a gestão de acesso as fontes informacionais); assimilável (leia-se comunicável, haja vista que uma fonte disponibilizada no Brasil, por exemplo, em mandarim, por meio de cadastros de acesso altamente burocráticos, softwares de navegabilidade complexos e sistemas de segurança da informação ultrapassados, dificilmente vão atender uma alta demanda por parte de usuários brasileiros). É comum vermos o termo "acesso à informação" sendo aplicado a tipologias documentais que simplesmente estão disponíveis em determinada instituição, plataforma virtual e afins, mas que não são acessadas pelo simples fato de haver barreiras quanto ao modo de acessar uma determinada base, desconhecimento de técnicas básicas de estratégias de busca para localizar uma informação específica ou mesmo desconhecimento por parte do usuário de que determinada fonte pode ser encontrada em um determinado lugar. 
Em termos didáticos podemos distinguir três dimensões para se pensar a problemática do acesso à informação: a dimensão física, a dimensão intelectual e a dimensão social. A primeira, envolve a infraestrutura material, eletrônica, virtual, geográfica e econômica como fatores que afetam o acesso à informação; a segunda, trata da compreensão do usuário, ou corpo social, sobre o a informação que almeja, sua organização, representação, meios físicos e cognitivos para que o mesmo obtenha uma determinada informação; a terceira, versa sobre o capital social, as regras sociais, as subjetividades e necessidades singulares de informação como aspectos essenciais para seu usufruto (GUIMARÃES; SILVA; NORONHA, 2011). Tendo em vista que o foco do trabalho não é realizar uma análise sobre o viés material, intelectual da informação, mas sim o viés social, haja vista que discorremos sobre uma problemática de cunho social, dado a importância e os possíveis efeitos da tipologia documental construída por intermédio da narrativa de pessoas presas, iremos focar nas implicações sociais sobre o acesso à informação, sem, contudo, deixar de demonstrar que essa divisão entre as dimensões de acesso são meramente didáticas, pois torna-se inviável o aprofundamento nas discussões de cunho social silenciando alguns fatores que estão mais intimamente ligados aos outros dois vieses citados.

Todavia, pensar a questão do acesso à informação, é discorrer sobre o seu efeito salutar ou violento para com o corpo social, haja vista que nem toda informação está acessível, pode estar acessível além de que o excesso de acessibilidade da informação - atrelado a determinado recorte, implicações midiáticas, ideológicas e afins - também podem ser categorizadas como perniciosas ao invés de acesso propriamente dito. Assim sendo, é mister um cuidado quanto ao conteúdo promovido de forma cada vez mais rápida por meio dos diversos fluxos informacionais, pois os efeitos oriundos das condições políticas de acesso se iniciam "no presente, para serem acessados no futuro" (MONTEIRO, 2019, p. 300).

Eis que em um primeiro momento podemos nortear a relação do acesso à informação as questões decorrentes do conceito de violência a partir dos pressupostos legais, ambiente no qual emerge "zonas de tensão, espaços de consenso, [dissenso] e práticas informacionais entre Estado e Sociedade, inerentes às dinâmicas requeridas pelo direito à informação" (JARDIM, 2012, p. 2). Para ilustrar, cabe um pequeno trecho dito por um dos internos apresentados no presente texto:

Hoje eu to pensando em voltar a estudar. Penso que no sistema deve ter como estudar. Quero ver se tem direito pra fazer faculdade (F., 1996: 32). 
Acesso à informação não pode ser visto apenas no sentido stricto sensu, a determinadas tipologias documentais, textos e afins. Deve-se ater primeiramente ao seu sentido lato, ou seja, os direitos aos quais temos e como adquirir acesso de fato a isso, em prol de uma linha de raciocínio que se inicia pelos critérios gerais e adentra nas especificidades inerentes a determinada demanda informacional, tipologia documental e pessoas as quais o acesso em questão se destina. Se todos temos a mesma igualdade de direitos perante a lei e se o art. 6 da Constituição diz que são direitos sociais: "a educação, a saúde, a alimentação, o trabalho, a moradia, o transporte, o lazer, a segurança, a previdência social, a proteção à maternidade e à infância, a assistência aos desamparados" (BRASIL, 1988, p. 3), é inegável que há de se prover um acesso disponível independente das circunstâncias em que o sujeito se encontre no país, pois vale ressaltar que a tipificação criminal atrelada a ficha de uma determinada pessoa pode lhe privar do direito à liberdade, porém não dos demais acessos que Ihes são resguardados em lei. Tanto que, para além da Carta Magna, a própria LEP endossa que a educação, tal como descrita no art. 18 e 18-A, é um direito natural e constitucional, no qual o ensino de primeiro grau é obrigatório, enquanto que os demais níveis de ensino serão incorporados nas unidades prisionais (BRASIL, 1984). Em adendo, o interno A. ao ser questionado sobre seus estudos, afirma:

Só [estudei] até a quarta série. Os amigos eram do trabalho (A., 1996: 35).

O amplo leque de informações, contidas nas leis supracitadas, não chegam às pessoas presas, pois em muitos casos narrados, o desconhecimento quanto aos seus direitos é algo recorrente, a ponto de questionarem se a prisão pode prover o acesso à educação, um dos direitos e vontades de alguns internos. Logo, a ausência de acesso à informação corrobora para o desconhecimento dos direitos sociais que Ihes são garantidos, além de propiciar o sucateamento de uma instituição que por si só, prioriza o investimento em segurança, contenção e punição ao invés da inserção social, o que acarreta as instituições de disciplina tais como escola, manicômio, hospitais, prisões e afins uma contradição entre a missão de prover apoio social ao mesmo tempo em que necessita afastar, alocar, disciplinar e em algumas instituições conter a pessoa que representa perigo e risco à sociedade (ROSA; MALFITANO, 2019). No caso da prisão, tem-se um espaço transformado, qualificado como gueto, tal qual os guetos periféricos em que muitos dessas pessoas habitavam antes de estarem sob custódia do Estado, dito de outra forma, "o gueto é uma 
forma de 'prisão social', ao passo que a prisão funciona como um 'gueto judiciário'"' (WACQUANT, 2007, p. 335).

Além da ausência de acesso aos direitos sociais previstos em lei e ao acesso à informação propriamente dito, têm-se uma comunicação segmentada sobre o que pode ser acessado pela sociedade em geral, por meio de pesquisas, relatórios e mídias de massa, em detrimento de todo um arcabouço disponível sobre as pessoas presas. Ocorre uma banalização das mídias e repetição de disseminação genérica, parcial ou mesmo equivocada de informação, tal como um processo de instauração do trauma social na sociedade, exemplificada por um viés discursivo estatal e midiático sobre o crime praticado por determinados sujeitos e sua proximidade como um ser perigoso que deve ser contido a todo custo, ao mesmo tempo em que se negligencia toda uma conjuntura de fatores violentos que cercam não apenas o sujeito antes, durante ou após sua estadia na prisão, mas também a toda sociedade, afinal de contas, problemas inerentes a ausência, ou deficiência do Estado, não afetam unicamente as pessoas presas, o que demonstra a potência de eclosão traumática ocasionada por uma enxurrada de imagens televisivas e demais tecnologias de armazenamento e informação que, nas palavras de Assmann (2011, p. 230) são um tipo de escrita que "já não permite qualquer distinção precisa entre recordar e esquecer".

Assim, é crucial prover o entendimento quanto aos efeitos positivos e ou negativos de determinado acesso à informação, pois "assim como o lembrar, o esquecimento é um ato social e histórico, e não um fenômeno espontâneo provocado pela passagem do tempo" (GONDAR, 2008, p. 97). Em acréscimo, as implicações políticas que proporcionam o evocar da memória, ou esquecimento, sobre determinado acesso, por si só é um meio que possibilita violências distintas, tais como: inequidade informacional sobre determinados acontecimentos, crimes, parcialidade quanto ao acesso ou restrições a informação, equívocos em investigações criminosas, negligência, ou ocultamento, quanto às ausências institucionais e estatais, por exemplo, narradas pelas pessoas presas, além do descumprimento aos artigos constitucionais, LEP e a própria Lei n. 12.527 , de 18 de novembro de 2011, a Lei de Acesso à Informação (LAI) - leis que deveriam ser aplicadas de forma igualitária - mas que demonstram constantes equívocos ou deturpações em suas aplicações ou inobservâncias.

Constata-se que discorrer sobre acesso envolve ao menos dois fatores: primeiro, o fato de que o acesso se dá em condições de grau, no qual determinadas fontes, conteúdos e pessoas possuem mais ou menos acesso; segundo, o fato de que o grau estabelecido para o acesso à informação, por ser uma escolha política, corrobora para efeitos salutares ou danosos, e por que não dizer violentos, quanto aos seus efeitos, pois 
negar o acesso à informação, que Ihe é de direito, seja uma pessoa presa em busca do entendimento sobre suas implicações processuais e criminais, um pesquisador que analisa determinadas conjunturas no âmbito prisional, saúde, trabalho, educação e demais condições garantidas por lei aos privados de liberdade ou mesmo acesso a pesquisas feitas por demais órgãos e civis, minimamente afeta seus direitos legais, além de tornar obscuro, as vastas violências narradas pelos internos, seus traumas, sendo condições que Ihes são impostas por toda sua conjuntura de vida, mas que devemos ter cautela em não negligenciar, pois muito do que essas pessoas narram também são violências praticadas de forma ativa, ou por meio de ausências, de familiares, do Estado e demais instituições aos que se encontram fora dos muros prisionais, portanto, apresentam dados, são fontes informacionais cujo acesso deve ser priorizado em detrimento do sigilo, tal como predispõe o inciso primeiro do art. 3 da LAI: "observância da publicidade como preceito geral e do sigilo como exceção" (BRASIL, 2011, p. 1).

A luta pelo acesso à informação não pode ser vista de forma equivocada com a banalização das interfaces comunicacionais e informacionais, tal como já discutido, pois da mesma forma que a restrição se mostra, em certa medida, perniciosa, o acesso, ou exacerbação da informação também o é, pois "o excesso de conhecimento dispersa-se indiferentemente na superfície em todas as direções, mas ele só comuta" (BAUDRILLARD, 1992, p. 18). Para que não ocorra essa comutação constante que bombardeia o receptor ao invés de propiciar o acesso à informação, é necessário que a política de acesso passe por uma constante revisão, de acordo com as inúmeras demandas do corpo social, além do Estado ter de prover condições para esse acesso, dirimindo equívocos, anulando burocracias, de forma a garantir o direito fundamental a todos, assegurado pela Constituição Federal (MERLO; KONRAD, 2015).

Logo, aplicar o olhar para os relatos sob o viés de uma tipologia documental singular, a evocar mais do que os crimes praticados pelos sujeitos, mas também os crimes que afligem aos próprios narradores, suas famílias, amigos e de forma mais sutil, indireta a sociedade em geral, é promover minimamente o diálogo, apresentar não só os dados de pesquisa, mas o produto, o resultado das pesquisas, os relatórios institucionais, de cunho acadêmico e da própria Secretaria de Estado de Administração Penitenciária (SEAP). Isso reforça a necessidade de envolver-se em uma pesquisa, adentrar no campo do crime e da violência sem enviesar-se pelo crime do sujeito estudado, mas sim na equivalência do crime perante os sujeitos, pois aplicar um olhar seletivo por meio das mídias, decisões jurídicas, política e ideológicas, é promover a 
categorização equivocada, estigmatizada do outro, o que denota, por si só, um viés criminoso (GROSSER, 1989).

Outrossim, sair da esfera unicamente da discussão e implementar, de fato, o acesso aos direitos sociais e pessoais, quanto aos dados sobre a tramitação processual, requerimento de estudo, progressão de regime e outros, é não apenas o cumprimento do já disposto em lei, mas também, a edificação e, por conseguinte, a manutenção de uma política que retira o sujeito da condição de ser segregado - por conta de escolhas oriundas de um plano estético, social e político enviesado (DOMINGUES, 1999) -, quebra barreiras sociais que o enquadram como um ser anormal em uma vida de percalços que Ihes seguem em um continuum indiviso, a não ser em termos didáticos, entre o passado presente e o futuro. Ademais, o acesso à informação de cunho pessoal e social integra as instituições na relação com a pessoa presa, em prol da coibição do sujeito a enveredar-se no caminho de sua identificação com o ato, o que lhe induz, e reduz, a um campo de possível repetição do crime, sendo uma violência no qual o algoz também se torna vítima devido ao caminho traumático que Ihe é induzido constantemente (KEHL, 2011).

O campo de discussões sobre o acesso à informação mostra-se fértil tendo em vista o quão abrangente esses estudos podem ser no que diz respeito as políticas públicas e ações afirmativas, cruzando com discussões, a priori, díspares como é o caso do crime, do trauma e da violência, essa a permear mais do que seus efeitos violentos inerentes as tipificações criminais e aos diversos impactos de ordem traumática, mas também a exercer possíveis efeitos danosos quando pensamos sobre a própria cultura, ou melhor, política informacional, aplicada pelas instituições e seus resultados que afetam o acesso por meio da morosidade, burocracia, deturpação, omissão e afins, de forma que é imperativo a necessidade de integração entre pesquisadores, analistas, arquivistas, profissionais da informação e afins para prover soluções salutares a questão do acesso e a preservação das tipologias documentais, independente da mesma ser física, digital ou virtual (MONTEIRO, 2018). É uma possibilidade para os profissionais da informação, educadores e demais categoriais que lidam com os processos informacionais e comunicacionais prover subsídios aos sujeitos que necessitam de determinada ajuda na obtenção de informação e, por conseguinte, resultar na construção do conhecimento, tornando-o habilitado, competente em suas buscas informacionais e uso de suportes complexos (ROJAS, 2005), de teor delicado e distinto, como é o caso dos documentos cuja narrativa registrada advém de pessoas presas. 


\section{Considerações finais}

Constata-se que o caráter plástico da tríade crime, trauma e acesso à informação por intermédio de suas respectivas relações com a violência, assim o é pois as três dimensões citadas não são estanques, estáticas, mas sim plurais em suas perspectivas de análise criminal e aplicação das respectivas tipificações, os diversos efeitos da violência como um processo que pode facultar o trauma da mesma forma em que possibilita sua elaboração, e a importância de revisitarmos o conceito de acesso à informação como um meio de ampliar nossa olhar para o que se entende por violência, além dos diversos segmentos de pessoas, presas ou não, utilizarem-se do direito de acessar dados, informações e construírem conhecimentos sobre atos que lhes acometem cotidianamente seja por instituições como família, Estado e afins. Têm-se uma gama de estruturas cuja influência nos corpos implicam que nos dedicamos a lhes direcionar uma luz, prover visibilidade, devido a sua plasticidade, dito de outra forma, a violência analisada sob a sua relação com a tríade supracitada evocam o quão tortuosos, confusos e inóspitos são os caminhos da pesquisa e do enfrentamento a violência propriamente dita, o que demonstra ser um problema que não pode ser tratado de forma reducionista ou enviesada, tal como soluções de embasamento curto e desprovido de análise conjuntural sobre as miríades da violência e seus efeitos no corpo social.

Alguns aspectos já são considerados, ainda que de forma parca, como diretrizes para pesquisas, construção e manutenção de políticas públicas que versem sobre a problemática da violência: a questão de gênero, faixa etária do grupo estudado, formação (aplica-se pelo viés do objeto de estudo ou do pesquisador), instituições, carga horária semanal (aplica-se aos que almejam acesso à informação, não ao que se encontra em privação de liberdade), cargo (aplica-se ao pesquisador ou ao cargo que a pessoa ocupava antes de ser presa ou tornar-se egresso do sistema prisional), instrumentos de pesquisa (base de dados, relatórios, entrevistas transcritas etc.), facilidades de utilização dos instrumentos citados, tipologia do usuário (pesquisador, próprio preso, egresso da prisão, professores, advogados, assistentes sociais, público em geral), exposição da necessidade de informação, uso da informação, aspecto da informação (se há qualidade, eficiência, eficácia etc.), restrição formal ou informal as informações, direito de acesso (se a pessoa está ciente de seus direitos sociais e de acesso à informação em si), treinamentos entre outros apontamentos que poderíamos trazer para enfatizar o quão imenso e disponível é o caminho para analisarmos o a tríade discutida por 
intermédio não só das narrativas das pessoas presas, mas também por aqueles que almejam o acesso a essa tipologia documental.

Em aditamento, também há um vasto campo para discutirmos sobre a questão da restrição informacional, apontada de forma simples na presente reflexão, torna-se um motor ratio para as futuras discussões. Eilas: restrição de ordem organizacional, financeira, recursos humanos, cultural, técnica, tecnológica. Entende-se que as restrições informacionais merecem um espaço de destaque aliado a reflexão sobre o acesso à informação, pois para além dos crimes, traumas e questões inerente ao acesso narradas pelas pessoas presas, muitos pontos demonstram a existência de uma estrutura perniciosa não apenas com os internos, mas também aos egressos das unidades prisionais e a própria sociedade, tendo em vista os problemas oriundos de uma restrição seja por problemas no planejamento do acesso, seja por questões éticas, políticas, ideológicas e afins. Por isso, verificamos que ainda há muito o que perscrutar e as narrativas apresentadas são um dos caminhos, uma voz que soma e contribui para possíveis avanços na diminuição de inequidades não apenas informacionais, mas sociais em sentido lato.

\section{Referências}

ALIGHIERI, Dante. A divina comédia. 4. ed. Belo Horizonte: Itatiaia, Brasília: INL, 1984. v. 1.

ASSMANN, Aleida. Espaços da recordação: formas e transformações da memória cultural. Campinas, SP: Unicamp, 2011.

BAUDRILLARD, Jean. A transparência do mal: ensaio sobre os fenômenos extremos. 2. ed. Campinas, SP: Papirus, 1992.

BAYARD, Jean Pierre. Sentido oculto dos ritos mortuários: morrer é morrer? São Paulo: Paulus, 1996.

BENJAMIN, Walter. Sobre a linguagem em geral e sobre a linguagem do homem. In: . Escritos sobre mito e linguagem (1915-1921). 2. ed. São Paulo; Duas Cidades; Editora 34, 2013.

BOHLEBER, Werner. Recordação, trauma e memória coletiva: a luta pela recordação em psicanálise. Revista Brasileira de Psicanálise, v. 41, n. 1, p. 154-175, 2007.

BUTLER, Judith. Quadros de guerra: quando a vida é passível de luto? Rio de Janeiro: Civilização Brasileira, 2015. 
BRASIL. Constituição. Constituição da República Federativa do Brasil de 1988. Poder Executivo, Brasília, DF, 5 out. 1988. Disponível em: http://www.planalto.gov.br/ccivil 03/Constituicao/Constituicao.htm. Acesso em: 12 abr. 2019.

BRASIL. Lei no 7.210 de 11 de julho de 1984. Institui a Lei de Execução Penal. Presidência da República, Brasília, DF, 1984. Disponível em: http://www.planalto.gov.br/ccivil 03/leis/l7210compilado.htm\&gt. Acesso em: 31 maio 2018.

BRASIL. Lei no12.527 de 18 de novembro de 2011. Regula o acesso à informação. Presidência da República, Brasília, DF, 2011. Dis ponível em: http://www.planalto.gov.br/ccivil 03/ ato20112014/2011/lei/l12527.htm. Acesso em: 8 maio 2019.

CERQUEIRA, Daniel; LOBÃO, Waldir. Determinantes da Criminalidade: Arcabouços Teóricos e Resultados Empíricos. DADOS - Revista de Ciências Sociais, Rio de Janeiro, v. 47, n. 2, p. 233-269, 2004. Disponível em: http://www.scielo.br/pdf/dados/v47n2/a02v47n2.pdf. Acesso em: 10 jul. 2019.

DOMINGUES, José Mauricio. Sociologia da Cultura, Memória e Criatividade Social. DADOS - Revista de Ciências Sociais, Rio de Janeiro, v. 42, n. 2, p. 1-17, 1999. Disponível em:

http://www.scielo.br/scielo.php?script =sci arttext\&pid=S0011 52581999000200004\&lng=pt\&nrm=iso. Acesso em: 10 jul. 2019.

ENDO, Paulo. Pensamento como margem, lacuna e falta: memória, trauma, luto e esquecimento. USP, São Paulo, n. 98, p. 41-50, jun./ago., 2013.

FARIAS, Francisco Ramos de (Org.). Apontamentos em memória social. Rio de Janeiro: Contra Capa, 2011.

FARIAS, Francisco Ramos de. Porque, afinal, matamos? Rio de Janeiro: 7Letras, 2010.

FARIAS, Francisco Ramos de. O ato criminoso como modalidade de gozo: subjetividade perversa e ato perverso. Rio de Janeiro: Fundação Biblioteca Nacional - Escritório de Direitos Autorais. pp. 445. No registro: 757.783; Livro: 1469; Folha: 274. 2018.

FOUCAULT, Michel. Vigiar e punir: nascimento da prisão. 39. ed. Petrópolis, RJ: Vozes, 2011. 
FREUD, Sigmund. Estudos sobre a histeria [1893-1895]. Companhia das Letras, Rio de Janeiro, 2016. v. 2.

FREUD, Sigmund. Psicologia das massas e análise do eu. Porto Alegre, RS: L\&PM, 2013.

GONDAR, Jô. Cinco proposições sobre memória social. Morpheus: revista de estudos interdisciplinares em memória social, Rio de Janeiro, v. 9, n. 15, 2016. Disponível em:

http://www.seer.unirio.br/index.php/morpheus/article/view/5475/4929\&g t. Acesso em: 12 abr. 2019.

GONDAR, Josaida de Oliveira. Memória, tempo e história. In:

BARRENECHEA, Miguel Angel de. As dobras da memória. Rio de Janeiro: 7Letras, 2008.

GOODE, William; HATT, Paul. O estudo do caso. In: . Métodos em pesquisa social. 5. ed. São Paulo: Nacional, 1975. p. 420-423, 1975.

GROSSER, Alfred. Le crime et al. mémoire. França: Flammarion, 1989.

GUIMARÃES, Maria Cristina Soares; SILVA, Cícera Henrique da; NORONHA, Ilma Maria Horsth. Acesso a la información como determinante social de la salud. Salud Colectiva, Argentina, v. 7, n. 1, p. 9-18, 2011.

JARDIM, José Maria. A lei de acesso à informação: dimensões políticoinformacionais. Tendências da Pesquisa Brasileira em Ciência da Informação, Paraíba, v. 5, n. 1, 2012.

KEHL, Maria Rita. Sua única vida. In: PERDOMO, Maria Cristina; CERRUTI, Marta (Org.). Memória, trauma e transmissão: a incidência da política na clinica psicanalítica. São Paulo: Primavera Editorial, 2011.

LESSA, Andrea. Arqueologia da agressividade humana. A violência sob uma perspectiva paleoepidemiológica. História, Ciências, Saúde Manguinhos, Rio de Janeiro, v. 11, n. 2, p. 279-296, maio/ago., 2004. Disponível em: http://www.scielo.br/pdf/hcsm/v11n2/03.pdf. Acesso em: 5 jul. 2019.

MERLO, Franciele; KONRAD, Glaucia Vieira Ramos. Documento, história e memória: a importância da preservação do patrimônio documental para o acesso à informação. Inf. Inf., Londrina, v. 20, no 1, p. 26-42, jan./abr., 2015. Disponível em: http://www.uel.br/revistas/uel/index.php/informacao/article/view/18705/ pdf 43. Acesso em: 8 maio 2019. 
MINAYO, Maria Cecilia de Souza; CONSTANTINO, Patricia. Deserdados sociais: condições de vida e saúde dos presos do Estado do Rio de Janeiro. Rio de Janeiro Fiocruz, 2015.

MINAYO, Maria Cecília de Souza; DESLANDES, Suely Ferreira; GOMES, Romeu. Pesquisa social: teoria, método e criatividade. Petrópolis, RJ: Vozes, 2016.

MINAYO, Maria Cecília de Souza; SOUZA, Edinilsa Ramos de. Violência e saúde como um campo interdisciplinar e de ação coletiva. História, Ciências, Saúde - Manguinhos, Rio de Janeiro, v. 4, n. 3, p. 513-531, nov./fev., 1998. Disponível em:

http://www.scielo.br/pdf/hcsm/v4n3/v4n3a06.pdf. Acesso em: 5 jul. 2019.

MITJAVILA, Myriam. Labirintos da medicalização do crime. Saúde soc., São Paulo, v. 25, n. 4, p. 847-856, 2016. Disponível em: http://www.scielo.br/pdf/sausoc/v25n4/1984-0470-sausoc-25-0400847.pdf. Acesso em: 5 jul. 2019.

MONTEIRO, Nercilene Santos da Silva. Democratizar a informação para o desenvolvimento do conhecimento: a ampliação do acesso ao acervo documental das ciências e da saúde na Fiocruz. História, Ciências, Saúde - Manguinhos, Rio de Janeiro, v. 26, n. 1, p. 299-318, jan./mar., 2019. Disponível em: http://www.scielo.br/pdf/hcsm/v26n1/0104-5970-hcsm26-01-0299.pdf. Acesso em: 5 jul. 2019.

PEREZ, Carlos Blaya; MENEZES, Priscila Lopes. O usuário e o direito à informação. Ponto de Acesso, Salvador, v. 1, n. 2, p. 49-69, jul./dez., 2007.

ROBERT, Philippe. Sociologia do crime. Petrópolis, RJ: Vozes, 2011.

ROJAS, Miguel Ángel Rendón. Relación entre los conceptos: información, conocimiento y valor: semejanzas y diferencias. Ci. Inf., Brasília, DF, v. 34, n. 2, p. 52-61, maio/ago., 2005. Disponível em:

http://revista.ibict.br/ciinf/article/view/1090/1198. Acesso em: 8 maio. 2019.

ROLIM, Marcos. Desistência do crime. Revista Sociedade e Estado, v. 33, n. 3, p. 829-847, 2018. Disponível em:

http://www.scielo.br/pdf/se/v33n3/0102-6992-se-33-03-00829.pdf.

Acesso em: 5 jul. 2019.

ROSA, Soraya Diniz; MALFITANO, Ana Paula Serrata. No meio do caminho tinha uma pedra: a história de violência e sofrimento social de jovens 
adultos com trajetórias de internação em hospital psiquiátrico. História, Ciências, Saúde - Manguinhos, Rio de Janeiro, v. 26, n. 2, p. 501-518, p. abr./jun., 2019. Disponível em:

http://www.scielo.br/pdf/hcsm/v26n2/0104-5970-hcsm-26-02-0501.pdf. Acesso em: 5 jul. 2019.

TOLEDO, Luciano Medeiros de; SABROZA, Paulo Chagastelles (Org.). Violência: orientações para profissionais da atenção básica de saúde. Rio de Janeiro: ENSP/Fiocruz, 2013.

W ACQUANT, Loic. A aberração carcerária à moda francesa. DADOS Revista de Ciências Sociais [online], Rio de Janeiro, v. 47, n. 2, p. 215232, 2004. Disponível em:

http://www.scielo.br/pdf/dados/v47n2/a01v47n2.pdf. Acesso em: 10 jul. 2019.

WACQUANT, Loic. As prisões da miséria. 2. ed. Zahar: Rio de Janeiro, 2011.

WACQUANT, Loic. Punir os pobres: a nova gestão da miséria nos Estados Unidos. 3. ed. Rio de Janeiro: Revan, 2007.

ZIZEK, Slavoj. Violência: seis reflexões laterais. São Paulo: Boitempo, 2014.

1 Gíria usada pela polícia para designar extorsão praticada pelos policiais.

$\underline{2} \mathrm{Na}$ mitologia grega, Minos consta como um semi-deus, filho de Zeus e da princesa fenícia da Europa, que reinou na ilha de Creta em aproximadamente 1406 a.C. a 1204 a.C. Na obra intitulada A divina comédia de Dante Alighieri, Minos é representado como um juiz do inferno que julga todos os que por lá passam, aplicando em cada sujeito um chicote, ou cauda, que, a cada volta enroscada no pecador, determina o quão mais profundo, abaixo da terra e, próximo ao diabo, este deverá pagar por suas mazelas. Minos antecede a entrada de cada alma aos portões do Inferno (ALIGHIERI, 1984). Cabe-nos questionar o direito que permite a todos adquirirem o status de juiz, tal como Minos e, além disso, refletir sobre a seletividade da punição aplicada a cada sujeito que, muitas das vezes, mesmo ao responder pela mesma tipificação criminal do outro, é alocado nas unidades prisionais em condições de tratamento diferenciado ou mesmo nem adentrando as celas por inúmeros fatores passíveis de reflexão. 